\title{
GESTÃO DE PESSOAS: RETENÇÃO DE TALENTOS E A DIMINUIÇÃO TURNOVER
}

\author{
Stela Galbardi de Resende ${ }^{1}$, Daniel Tavares Coelho ${ }^{2}$ \\ ${ }^{1}$ Faculdade Astorga, Mestranda PPE/UEM, Astorga, PR. E-mail: stela.galbardi@gmail.com \\ ${ }^{2}$ Faculdade Astorga, Astorga, PR. União de Faculdades Metropolitanas de Maringá, Maringá, PR.
}

\section{RESUMO}

Cada dia mais é possível notar gerentes e profissionais de recursos humanos preocupados com planos de retenção de talentos e a diminuição da rotatividade. O Objetivo desta pesquisa visa compreender o tema Retenção de Talentos por meio da liderança na empresa Loja Dez - ToledoPR. Buscou-se respostas para as seguintes inquietações: como deve ser o perfil de um gestor que retém talentos? Quais as ações da liderança refletem na diminuição do turnover? A pesquisa apresentou os seguintes resultados: a empresa consegue reter talentos mediante ao posicionamento de priorizar o fator humano, a qualidade de vida do funcionário é uma prioridade para a empresa. O perfil de líder encontrado foi o de sempre aberto ao diálogo; que considera o funcionário parte de sua família e então não somente deseja o bem para ele, mas luta para tal.

Palavras-chave: Retenção de Talentos; Rotatividade; Endomarketing.

\section{MANAGEMENT OF PERSONS: RETENTION OF TALENTS AND THE REDUCED TURNOVER}

\begin{abstract}
Everyday we notice that human resource managers and professionals are becoming more concerned with plans to retain talented professionals and reduced turnover. The objective of this research aims to understand the topic "Retaining Talented Professionals" through leadership in the company Loja Dez - Toledo-PR, Brazil. We sought for answers to the following concerns: How should the profile of a manager who retains talent professionals to be like? What should the approach be in terms of leadership to result in a decrease on turnover? The survey showed the following results: that the company can retain talent through the positioning of prioritizing the human factor and not only achieve sales targets, which means, the quality of life of the employee is a priority for the company. The best profile for a leader resulted in always being approachable to communicate openly to staff, making the employee to feel as part of the family, not only wish him well, but make an effort to do so.
\end{abstract}

Keywords: Retain talent; Turnover; Endomarketing.

\section{INTRODUÇÃO}

A Retenção de Talentos é um tema relevante e constante nas empresas, haja vista que segundo pesquisa realizada pela consultoria Deloitte ${ }^{1}$, no final de $201154 \%$ dos executivos apontou a Retenção como o principal desafio de 2012. De acordo com estudo realizado pela HayGroup ${ }^{2}$, $51 \%$ das empresas enfrentaram problemas de retenção em 2013, ou seja, a maioria. Embora seja

\footnotetext{
1“Deloitte" é a marca sob a qual dezenas de milhares de profissionais dedicados de firmas independentes em todo o mundo trabaIham em colaboração a fim de entregar serviços de Auditoria, Consultoria, Assessoria Financeira, Gestão de Riscos, Consultoria Tributária, e serviços relacionados, a uma seleta carteira de clientes, localizada em SP.

${ }^{2} O$ HayGroup é uma empresa global de consultoria de gestão de negócios, que trabalha com líderes com a finalidade de transformar estratégia em realidade, no Brasil está localizada no RJ e SP.
} 
um tema de grande impacto e importância segundo as próprias empresas estudadas pela HayGroup, 89\% delas não tem nenhum programa de retenção estruturado.

Sobre a busca por talentos, temos por Chiavenato que:

Gerir talento humano está se tornando indispensável para o sucesso das organizações. Ter pessoas não significa necessariamente ter talentos. $E$ qual a diferença entre pessoas e talentos? Um talento é sempre um tipo especial de pessoa. E nem sempre toda pessoa é um talento. Para ter talento a pessoa precisa ter algum diferencial que a valorize. (CHIAVENATO, 2004, p. 52)

Ele afirma ainda que:

As pessoas inteligentes de uma empresa são como elementos impulsionadores da organização e capazes de dotá-la de inteligência, talento e aprendizados indispensáveis à sua constante renovação e competitividade em um mundo de mudanças e desafios. As pessoas como fonte de impulso próprio que dinamiza a organização e não como agentes passivos, inertes e estáticos. (CHIAVENATO, 1999, p.8)

A vantagem competitiva de uma empresa está relacionada com o seu capital intelectual, ou seja, funcionários capacitados e preparados para o cenário atual. Sabe-se ainda que na competição econômica global da sociedade da informação, a capacidade de inovar a política das pessoas constituirá o diferencial competitivo das organizações e dos países. (TACHIZAWA, 2001, p.23)

Diante do exposto surgiram as seguintes inquietações: Como deve ser o perfil de um gestor que retém talentos? Quais as ações da liderança refletem na diminuição do turnover? O Objetivo desta pesquisa visa compreender o tema Retenção de Talentos através da liderança na empresa Loja Dez - Toledo-PR. Tendo como objetivos específicos: a) Comparar a teoria original fazendo uma análise histórica sobre o tema escolhido; b) Levantar e analisar o relacionamento patrão empregado pela empresa objeto deste estudo; c) Analisar as intenções das ações de Retenção dos funcionários realizadas pelas empresas.

\section{METODOLOGIA}

Quanto a metodologia utilizada, trata-se de uma pesquisa descritiva de caráter documental com abordagem qualitativa e quantitativa das ações da Liderança da empresa estudada. Segundo Malhotra (2001, p.155), "a pesquisa qualitativa proporciona uma melhor visão e compreensão do contexto do problema, enquanto a pesquisa quantitativa procura quantificar os dados e aplica alguma forma da análise estatística". E para a construção da estrutura teórica que fundamenta a pesquisa por meio de levantamento bibliográfico sobre o tema em questão. Quanto a coleta de dados, a pesquisa foi feita por meio de entrevista, questionários subjetivos e objetivos aplicados durante três dias. Primeiramente foi realizada a entrevista com a proprietária e administradora das lojas por meio de questionário subjetivo com doze questões. Depois o mesmo método foi adotado para os quatros funcionário que trabalham a mais tempo na empresa, acima de sete anos. Por último foi aplicado um questionário objetivos com todos os demais colaboradores presentes no dia, todos aceitaram responder.

\section{RESULTADOS}

O Modelo de Gestão de pessoas vem sofrendo significativas mudanças em função da livre concorrência, afirma Knapik (2006). Esta exigência do mercado por mudanças na empresa se justifica no ritmo de negócios, mudanças tanto comportamentais como organizacionais. Ainda sobre isto Knapik salienta:

O desafio da área de gestão de pessoas consiste principalmente na produção do equilíbrio entre os aspectos relativos ao comportamento humano e 
os subsistemas da gestão de pessoas dentro de uma cultura organizacional. (KNAPIK, 2006)

Cultura esta que vem tendo a necessidade de, em seu resultado final, atender ao mercado competitivo e às exigências que a globalização impõe, mas sem deixar de atender os aspectos humanos das relações e a qualidade de vida.

Ainda de acordo com Chiavenato:

a Gestão de Pessoas é uma das áreas que mais tem sofrido mudanças e transformações nestes últimos anos. Não apenas nos seus aspectos tangíveis e concretos como principalmente nos aspectos conceituais e intangíveis. A visão que se tem hoje da área é Totalmente diferente de sua tradicional configuração, quando recebia o nome de Administração de Recursos Humanos. Muita coisa mudou. (CHIAVENATO, 2004)

A Gestão de Pessoas a muito tempo deixou de se restringir a contratar, demitir e outras ações em torno disto, ela tem sido a responsável pela excelência das organizações prósperas e mais do que tudo, pelo aporte de capital intelectual que simboliza a importância do fator humano em plena Era da Informação e tecnologia.

Admitindo este novo cenário, as práticas de Gestão de Pessoas voltadas para a Retenção de Talentos passam impreterivelmente pelo recrutamento e seleção; treinamento e desenvolvimento; remuneração; entendimento dos motivos da alta rotatividade (turnover) e a compreensão do endomarketing.

Chiavenato (2000, p. 197) afirma que recrutamento é "um conjunto de técnicas e procedimentos que visa a atrair candidatos potencialmente qualificados e capazes de ocupar cargos dentro da organização". Sendo assim, antes de recrutar, captar e selecionar pessoas é necessário saber o que se espera delas, qual é o objetivo da empresa com os cargos que elas irão ocupar. E então, definir técnicas e procedimentos a fim de atrair candidatos habilitados à função, capazes der suprir estas necessidades da empresa ou ir além, pois após a contratação vê-se a importância de aperfeiçoamento e treinamento periodicamente. Toda empresa busca resultados, e para que os resultados atinjam os objetivos, a empresa, em alguns momentos, precisa treinar e desenvolver os seus colaboradores. É necessário proporcionar ao funcionário oportunidades de desenvolvimento pessoal e profissional e condições satisfatórias de trabalho em todos os sentidos (AQUINO, 1980).

O principal objetivo do treinamento é preparar o colaborador para desempenhar de maneira excelente, tarefas específicas do cargo que ocupa, ou que deve ocupar; através da melhoria de suas competências. Uma vez que todas estas melhorias refletem diretamente na rotina de trabalho dos empregados já treinados é consequência os resultados empresariais obter progressos significativos. Por outro lado, há que se considerar que a motivação do colaborador participante deste progresso passa por sua remuneração.

A remuneração é, sem dúvida, a ferramenta de retenção de talentos mais difundida na gestão de recursos humanos, isso porque ela é a contrapartida por excelência de qualquer trabalho: abstraindo relações de produção não capitalistas como escravidão e servidão, todo serviço prestado (físico ou intelectual) é, via de regra, financeiramente recompensado. (OLIVEIRA, 2008).

Admitindo o termo remuneração no mesmo sentido que compensação, Chiavenato (2003) diz que a compensação é a área que lida com a recompensa que o indivíduo recebe como retorno pela execução de tarefas organizacionais. Deste modo, dá-se o nome de compensação ao sistema de incentivos e recompensas que a organização estabelece para remunerar e recompensar as pessoas que nela trabalham (financeiras e não financeiras). Dessa maneira a compensação envolve a remuneração sob todas as suas formas possíveis, e quando esta não é satisfatória, entre outros motivos, pode-se perder o colaborador, contribuindo assim para o turnover empresarial. 
A rotatividade se refere ao fluxo de entradas e saídas de pessoas em uma organização. Cada desligamento corresponde à admissão de um substituto como reposição. Existem duas formas de desligamento dos colaboradores de uma organização: o desligamento por iniciativa do funcionário ocorre quando decide, por razões pessoais ou profissionais, encerrar a relação de trabalho com o empregador e a outra forma é desligamento por iniciativa da organização, quando a empresa decide realizar o desligamento do colaborador (CHIAVENATO, 2004).

Vejamos as afirmações de Chiavenato e analisemos a figura a seguir:

O termo rotatividade de recursos humanos é usado para definir a flutuação de pessoal entre uma organização e o ambiente [...] a rotatividade de pessoal é expressa por meio de uma relação percentual entre as admissões e os desligamentos com relação ao número médio de participantes da organização, no decorrer de certo período de tempo. (CHIAVENATO, 2000, p.178)

E ainda:

Algumas vezes, a rotatividade pode escapar ao controle da organização, quando os desligamentos efetuados por iniciativa dos empregados aumentam de volume. Em um mercado de trabalho competitivo e em regime de oferta intensa, costuma ocorrer aumento da rotação de pessoal. (CHIAVENATO, 2000, p.179)

Ao fluxo de entrada e saída dos funcionários, dá-se o nome de rotatividade de pessoal ou turnover. Caso os desligamentos sejam provocadas pela empresa com a finalidade de melhorar o potencial humano existente admitindo recursos humanos de melhor qualidade encontrados no mercado, então a rotatividade desta encontra-se sob controle. Porém, quando os desligamentos são voluntários e independem da organização, esta rotatividade precisa ser analisada para localizar os motivos do turnover.

Quando se trata de rotatividade que independem da organização, o cálculo do índice de rotatividade é baseado no volume de contratações (entrada) e demissões (saídas) de pessoal em relação aos recursos humanos disponíveis na organização dentro de um período de tempo.

Dentre as variáveis externas estão a situação de oferta e procura do mercado de Recursos Humanos, a conjuntura econômica, as oportunidades de empregos no mercado de trabalho, dentre outras. Entre as variáveis internas estão a política salarial e de benefícios que a organização oferece, o estilo gerencial, as oportunidades de crescimento interno, o desempenho dos cargos, o relacionamento humano e as condições físicas e psicológicas de trabalho (CHIAVENATO, 2004).

Uma pesquisa realizada pela Infojobs $^{3}$ sondou mais de 30.000 profissionais. Cada um deles atribuiu valores de 1 a 5 (do menos ao mais importante) para possíveis fatores que estimulam uma troca de emprego. No ranking elaborado por eles em 2012 dos principais motivos do turnover nas empresas são: Plano de carreira; Reconhecimento profissional; Salário melhor; Benefícios relacionados à qualidade de vida; Ambiente de trabalho; Flexibilidade de horários; Participação nos lucros; Responsabilidade social; Novos desafios e Oportunidade de assumir um cargo de liderança.

O estudo também revela que aspectos devem ser melhorados pelas empresas para assegurar a retenção de funcionários. São eles: investimento em treinamentos, planos de carreira claros e programas motivacionais que contribuem inclusive para o Endomarketing. O termo "endo", do grego "edón", significa para dentro. Logo, o endomarketing consiste em vender uma ideia para o cliente interno, ou seja, o funcionário da empresa. Se de certa forma existe um trabalho de comu-

\footnotetext{
${ }^{3}$ InfoJobs é uma plataforma de oportunidades profissionais e busca de talentos que oferece ferramentas avançadas para gerir os processos seletivos das empresas e facilitam o aos candidatos a vantagem de cadastrarem seus currículos de forma gratuita, contemplando profissionais de todos os perfis. Infojobs.com.br iniciou suas operações no Brasil em 24 de março de 2004 como Infoemprego.com.br. Em Fevereiro de 2007 recebeu uma nova plataforma tecnológica e uma nova marca: InfoJobs.com.br.
} 
nicação feito para clientes externos e consumidores (para posicionamento da empresa ou promover um produto, por exemplo), o endomarketing tem o papel de executar ações similares internamente. Estas ações são focadas no bem-estar dos colaboradores, o que, consequentemente, melhora a produção e a capacidade intelectual das equipes. (LAUER, 2012). Pessoas felizes produzem mais e melhor, essa é a essência do endomarketing, que deve ser utilizado para a retenção de talentos e consequentemente na diminuição da rotatividade de pessoal.

Cada dia mais é possível notar gerentes e profissionais de recursos humanos preocupados com planos de retenção de talentos, pois o mercado, cheio de possibilidades, está tornando mais fácil a rotatividade daqueles profissionais insatisfeitos (LEISER, 2011). De acordo com Chiavenato (2009, p. 173) "as pessoas constituem o capital humano da organização. Esse capital pode valer mais ou menos, na medida em que contenha talentos e competências capazes de agregar valor à organização e torná-la mais ágil e competitiva". A valorização das pessoas na organização é de importância fundamental, pois cada vez mais elas são vistas como um diferencial de competência das empresas, para que se sintam valorizadas as mesmas necessitam de direcionamento para realizar suas funções com mais eficiência, eficácia e efetividade.

Como estabelece Chiavenato (2009, p 209):

Essa interação pode ser explicada como um processo de reciprocidade baseada em um contrato psicológico, recheado de expectativas recíprocas que regem as relações de intercâmbio entre pessoas e organizações. As organizações oferecem incentivos ou alicientes enquanto as pessoas oferecem contribuições. O equilíbrio organizacional depende do intercâmbio entre os incentivos oferecidos às pessoas e as contribuições deste como retorno à organização.

Conforme análise de Bauer (2008, p. 10) "no que diz respeito às pessoas, as empresas oferecem empregos e salários, sim, mas também stress, violação da personalidade, alienação, sufocamento do talento e, em muitos casos, infelicidade".

Então, mais do que reduzir os índices de turnover, reter os talentos da empresa é um desafio e tanto. O cumprimento com excelência do objetivo empresarial passa necessariamente pelas pessoas da organização. Sendo assim, faz-se imperativo planejar deste o recrutamento e contratação até os treinamentos periódicos a fim de ter o controle de cada etapa onde cada funcionário está e na busca da melhoria das suas competências sem negociar a remuneração proporcional fazê-lo sempre motivado e satisfeito.

\section{DISCUSSÃO}

A pesquisa foi realizada na cidade de Toledo-PR. De acordo com o site da Prefeitura Municipal, Toledo tem 119.313 habitantes, sua principal economia é Agroindustrial. Tem o 10 lugar em parque industrial do oeste do Paraná com 553 indústrias; 1.792 estabelecimentos comerciais e 6.473 empresas cadastradas na prefeitura (uma empresa para cada 16 habitantes).

A empresa pesquisada foi a LOJA DEZ dos proprietários Leni Adriana da Silva e Henrique da Silva que possuem 4 lojas entre as cidades de Toledo, Cascavel, Assis Chateaubriand e Marechal Cândido Randon todas no estado do Paraná; também possuem uma fábrica em Toledo. A empresa trabalha no ramo de confecções e vestuário. Tem como missão oferecer a população do oeste do Paraná roupas com qualidade, bom preço e ótimo atendimento. Ao todo a empresa possui 49 funcionários, destes 34\% estão trabalhando a mais de 5 anos nesta empresa, o que justifica a escolha desta empresa para ser objeto de estudo. Das empresas deste grupo, foi escolhida para aplicação da pesquisa a LOJA DEZ FASHION situada na cidade de Toledo-PR que tem no total vinte e sete funcionários. Ao contrário do que o nome da empresa parece sugerir os preços praticados dos produtos não são dez reais. 
Após a aplicação dos questionários e coleta de dados, extraíram-se os resultados expostos nas próximas páginas. Dos colaboradores entrevistados $67 \%$ estão na empresa a menos de um ano, devida a ampliação da empresa e abertura do novo seguimento. Que estão na empresa de 2 a 5 anos foram 25\% e 8\% mais de 6 anos na empresa.

As questões objetivas foram aplicadas com os funcionários que tem menos de 7 anos na empresa. Como pode ser visto a maioria está a menos de um ano trabalhando nesta empresa.

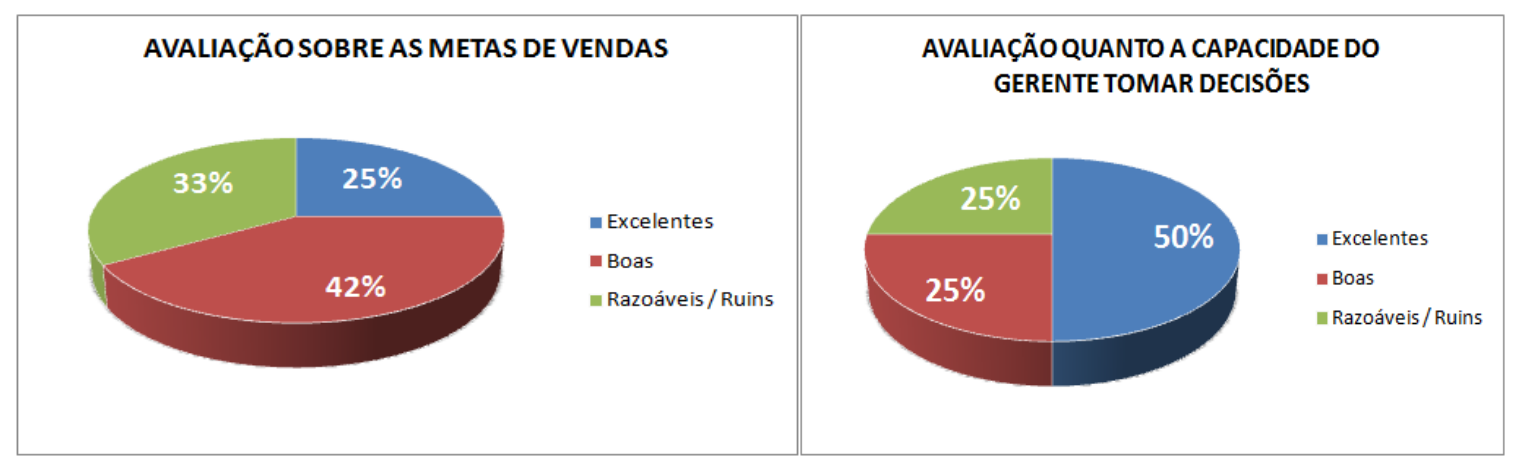

Vê-se que funcionários avaliaram as metas como alcançáveis, uma vez que a empresa possui três tipos de meta, a comissão e benefícios aumentam proporcionalmente. A concentração da avaliação como razoável ou ruim ficou com os que têm menos de 1 ano de tempo de serviço. Nota-se também que o grau de contentamento com a capacidade dos gerentes de tomarem decisões é superior ao descontentamento. Sendo que a porcentagem dos que avaliaram como razoável ou ruim se concentra nos funcionários que tem menos de 1 ano de tempo de serviço.

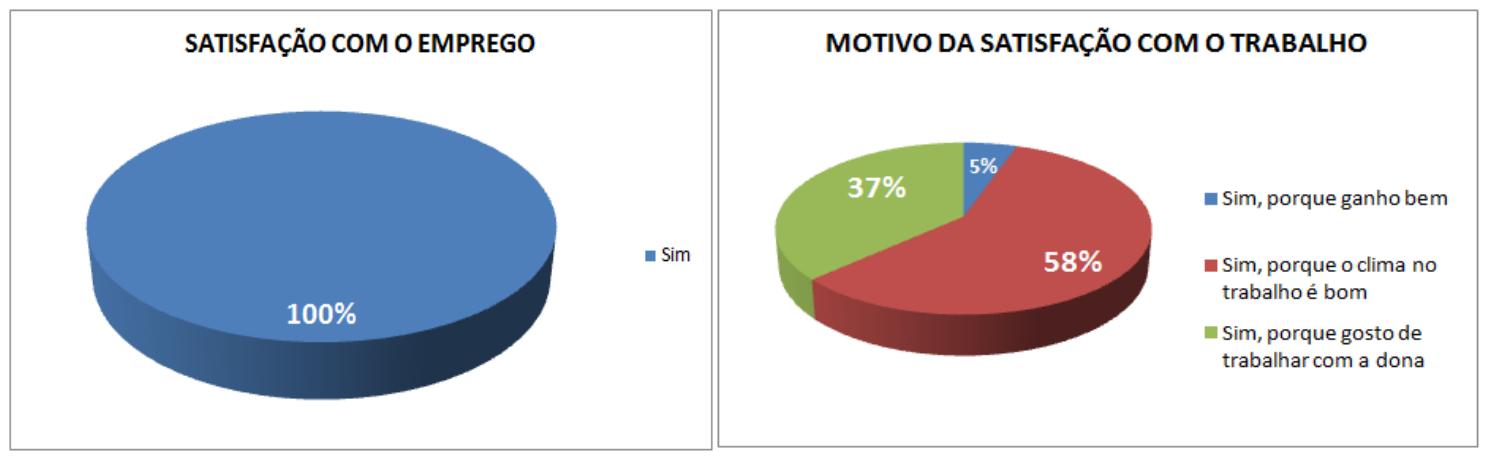

Nenhum funcionário disse estar insatisfeito ou buscando ainda a satisfação. Todos se consideram satisfeito. Percebe-se ainda que a maioria se diz satisfeito com seu trabalho referenciando ao clima de trabalho. A quase imperceptível porcentagem referindo-se ao salário mostra que, nesta empresa, o salário não é o principal motivo de satisfação, nem de perto comparado ao atendimento da empresária e do clima de trabalho.

Sabe-se que o clima está diretamente ligado à cultura da organização, pois esta reflete diretamente do resultado final, ou também, que o resultado final revela muito da cultura da organização. Sobre isso, na aplicação do questionário/entrevista com os funcionários que trabalham nesta empresa a mais de 7 anos, quando perguntado sobre o diferencial da empresa que justifique o tempo de serviço, disseram:

"...a liberdade, tipo quando tenho algum problema e preciso chegar atrasada, existe o entendimento, tipo assim, a compreensão. Tipo, tem todo um diálogo que consegue ser resolvido, e eu acredito que em outros lugares isso não teria." (entrevistado 1 - tempo de serviço: 7 anos). 
"...seria de sempre tá aberto, porque quando a gente assim precisa de algo, eles assim, eles fazem, entende? Se eu falar que eu preciso de algo, meu Deus, eles nesta parte assim é uma, por isso que eu falo se for para eu sair e trocar essa por outra loja eu não troco, eu fico aqui, é um ponto que eu creio que eles ganham das outras empresas, se eu preciso de algo eles dão um jeito, e isso é bem bacana."

(entrevistado 2 - tempo de serviço: 10 anos).

"...ah é o tratamento que eles tem com a gente, o clima de família, de união, é amizade, acho que acima de tudo de amizade." (entrevistado 3 - tempo de serviço: 10 anos).

"...diferencial? é, é, tem as cobranças mas te tratam como família, você é uma família aqui dentro, entendeu? Se você tem algum problema, é assim, existe muito diálogo, tem as reuniões de manhã que é bem gostoso, nessa parte você não é aquela empresa que você chega, bate cartão trabalha, trabalha, trabalha bate o cartão e vai embora, a convivência é familiar e isso ajuda muito. (entrevistado 4 - tempo de serviço: 11 anos).

Levando em consideração de que não foi agendado com a empresa, e que nem mesmo os funcionários sabiam da entrevista, ficou claro que a cultura está bem definida nas falas "compreensão"; "sempre tá aberto"; "o clima de família, de união, é amizade"; e "te tratam como família".

$\mathrm{Na}$ entrevista com a empresária, quando perguntado quais ações que eles praticam que ela acredita ser crucial para manter o funcionário na empresa, ela responde:

“...olha a base de um bom relacionamento pra mim dentro da empresa e para manter o funcionário é o respeito, eu gosto de tratar com igualdade, a gente procura estimular com comissões mais bonificações."

(empresária)

A missão da loja fala de ótimo atendimento, e na visão da empresária isso não seria possível se não houvesse boas contratações, treinamentos e aperfeiçoamentos, mas o que ela considera mais importante para reter os talentos, de tal forma que jamais mudaria na rotina de trabalho é:

"...jamais mudaria, é, nos reunirmos todas as manhãs e fazer nosso devocional, ali tiramos um tempo primeiro para adorar a Deus, tentamos passar para eles que Deus é tudo na nossas vidas e que sem Ele não somo nada. Após o devocional sempre fazemos uma dinâmica, uma brincadeira. Então estes 20 minutos que passamos de manhã eu não mudaria não. Assim, até para nossa convivência né? Ser mais harmoniosa, mais próxima dos outros." (empresária)

Essa decisão reflete diariamente na qualidade de vida dos funcionários e revela a preocupação da empresa com o fator humano e os aspectos intangíveis que fala Chiavenato (2004).

Quando questionados sobre a liberdade que eles têm de participarem do processo decisório e sugerir melhorias na loja eles afirmaram:

“... eu acredito que sim, as vezes em forma de reunião ou eu e a Lê e mais alguém, e sempre sou recebida bem." (entrevistado 1 - tempo de serviço: 7 anos). 
"... eles sempre nos escuta, abrem sugestão, as vezes não fazem mas reflete e coloca alguma coisa em prática né? Em tudo mais eles colocam na balança, eles analisam né?."

(entrevistado 2 - tempo de serviço: 10 anos).

"... sempre ouvem as nossas opiniões, nem sempre acatam, as vezes eles poderiam melhora alguma coisa ou não, mas sempre ouvem, ouvem e trocamos ideias tanto em reunião como assim no dia a dia a gente senta, conversa, toda hora que a gente precisa conversar eles são abertos para ouvir, não tem um ah agora não posso, sempre para o que tá fazendo pra gente conversar." (entrevistado 3 - tempo de serviço: 10 anos).

“...bastante! a gente procura e sempre quando é necessário a gente expõe, sabe que a mudança não é de uma hora pra outra, mas as coisas mesmo com as limitações, a gente sabe, mas vê que eles correm atrás pra melhorá, isso é bom, dentro do possivel eles corre atrás pra melhorá." (entrevistado 4 - tempo de serviço: 11 anos).

No final da entrevista o entrevistado 2 e 4 disseram:

"...eles deixam essa liberdade de comunicação, então é bem bom isso numa empresa né, Ele ouvi nós também né, por as vezes empresas eles só falam e muitas vezes não querem ouvir o funcionário né, mas aqui são bons nisso ixi".

"...até porque eles não é de ficar só mandando, mas também põe a mão na massa. Manda sim porque tem que manda mas faz também. Existe muito companheirismo, todo trabalho tem dificuldades tem conflitos tem problema mas é acima de tudo no final o companheirismo prevalece, assim, é gostoso nessa parte, então, eu acho que o diferencial é esse."

Estas falas refletem que a comunicação, o sabe ouvir e o parar tudo para escutar o funcionário são ações que geram a satisfação tanto profissional como pessoal de cada indivíduo inserido na empresa.

Sobre ações de endomarketing, por exemplo, a empresa admitiu estar sendo falha quanto à exposição da visão, missão e valores, mas acredita que diariamente passa a cada funcionário estes conteúdos que são definidos. Isso se confirma na fala de um entrevistado "a gente sempre brinca que tudo aqui não é de dez reais, mas é dez no atendimento, dez na qualidade."

\section{CONCLUSÃO}

Na realização deste estudo, buscou-se discutir as ações de uma liderança no que tange a Gestão de Pessoas para a retenção de talentos. Por meio de observação, entrevistas e aplicação de questionário procurou-se encontrar e analisar as ações cruciais para reter talentos. Compreendeu-se com o estudo do tema "Retenção de Talentos" em suas raízes mediante a pesquisa bibliográfica que proporcionou a visão científica para a realização das análises da empresa.

Considerando o referencial teórico utilizado para realização desta pesquisa e o confronto sobre o tema escolhido, a conclusão foi que a empresa consegue reter talentos mediante ao posicionamento de priorizar o fator humano e não somente o atingir das metas de vendas. Prioridade esta que ficou claro a cada resposta e a cada fala, ou seja, a qualidade de vida do funcionário é uma prioridade para os empresários, que entendem ser parte da vida deles que existe também para contribuir. Após levantamento e análise comparativa como objeto deste estudo, a empresa atende aos conceitos consolidados até o momento de Retenção de Talentos. Embora os empresários não definiram etimologicamente o endomarketing, suas ações refletem que pessoas felizes trabalham mais e melhor. O perfil de líder encontrado foi o de sempre aberto ao diálogo; que con- 
sidera o funcionário parte de sua família e então não somente deseja o bem para ele, mas luta para tal.

Sugere-se que os empresários consigam delegar algumas ações a gerentes capazes de continuar este processo e assim focar na melhor estruturação que desejam. Sem ter a pretensão de esgotar o tema, o artigo buscou apresentar parâmetros para reflexão sobre o tema Retenção de Talentos, abrindo assim oportunidades para novas pesquisas.

\section{REFERÊNCIAS BIBLIOGRÁFICAS}

AQUINO, Cléber Pinheiro de. Administração de recursos humanos: uma introdução. São Paulo: Atlas, 1980.

BAUER, Ruben. Gestão da Mudança: caos e complexidade nas organizações. 1 ed. - 6. reimpressão - São Paulo: Atlas, 2008.

BRUM, Analisa de Medeiros. Endomarketing de A a Z: Como alinhar o pensamento das pessoas à estratégia da empresa. São Paulo: Integrare, 2010.

CHIAVENATO, Idalberto. Administração de Recursos Humanos. 7.ed. ver. e atual. São Paulo: Manole, 2009.

. Gestão de Pessoas. 2.ed. Rio de Janeiro: Elsevier, 2004.

. Remuneração, benefícios e relações de trabalho: como reter talentos na organização. 3. ed. São Paulo: Atlas, 2003

. Recursos Humanos. Ed. Compacta. 6. ed. São Paulo: Atlas, 2000.

. Gestão de Pessoas, o novo papel dos recursos humanos nas organizações.

1ed. Rio de Janeiro: Campus, 1999.

DUTRA, Joel Souza. Gestão de pessoas: modelo, processos, tendências e perspectivas. São Paulo: Atlas, 2008.

INFOJOBS. 10 motivos para mudar de emprego. Disponível em: http://exame.abril.com.br/carreira/noticias/10-motivos-para-mudar-de-emprego. Acesso em fev $\underline{2014}$.

INSTITUTO BRASILEIRO DE GEOGRAFIA E ESTATÍSTICA - IBGE. Cidades. Disponível em: < http://cidades.ibge.gov.br/>. Acesso em set. 2014.

KNAPIK, Janete. Gestão de pessoas e talentos. Curitiba: Ibpex, 2006.

LAUER, Caio. Endomarketing: significado e propósitos. 2012. Disponível em: http://www.catho.com.br/carreira-sucesso/gestao-rh/endomarketing-significado-e-propositos.

Acesso em fev 2014.

LEISER, Tatiane. $\mathbf{O}$ que retém talentos?, 2011. Disponível em: http://www.catho.com.br/carreirasucesso/gestao-rh/o-que-retem-talentos. Acesso em fev. 2014 
MALHOTRA, N. Pesquisa de marketing. 3.ed. Porto Alegre: Bookman, 2001.

OLIVEIRA, Sabrina Rossi de. Duas perspectivas na captação e retenção de talentos: os dilemas da empresa e do funcionário. http://www.lume.ufrgs.br/bitstream/handle/10183/16604/000686070.pdf?...1. Acesso em 05 jun 2014.

PREFEITURA MUNICIPAL DE TOLEDO. http://www.toledo.pr.gov.br/portal/cidade-conhecatoledo/cidade-conheca-toledo Acesso em out 2014.

TACHIZAWA, Takisky; FERREIRA, Victor Claudio Paradela; FORTUNA, Antônio Alfredo Mello. Gestão com Pessoas, uma abordagem aplicada às estratégias de negócios. 1ed. Rio de Janeiro: FGV, 2001, p.23

VERGARA, S. C. Gestão de pessoas. 2. ed. São Paulo: Atlas, 2000. 